\title{
Crack propagation in a brittle DCB specimen assessed by means of the Williams' power expansion
}

\author{
Lucie Malíková \\ Institute of Structural Mechanics, Brno University of Technology (BUT), Brno, Czech Republic \\ malikova.l@fce.vutbr.č, http://orcid.org/0000-0001-5868-5717
}

Seyed Mohammad Javad Razavi, Filippo Berto

Department of Mechanical and Industrial Engineering, Norwegian University of Science and Technology (NTNU), Trondheim, Norway

javad.razavi@ntnu.no,http://orcid.org/0000-0002-2574-065X

filippo.berto@ntnu.no,.bttp://orcid.org/0000-0002-4207-0109

\begin{abstract}
A double cantilever beam geometry has been chosen in order to investigate the importance of the higher-order terms of the Williams' power expansion for the crack path estimation. The crack propagation has been tested experimentally on a brittle polymethylmethacrylate (PMMA) specimen and although the mode I loading conditions were applied, the crack kinked from its original plane immediately and propagated towards the bottom side of the specimen. It has been shown that this phenomenon is connected to the magnitude and sign of the $T$-stress and to the level of the constraint generally. In this work, the influence of the third and higher terms of the Williams' series on the crack propagation is investigated. The generalized form of the well-known maximum tangential stress fracture criterion for determination of the crack propagation angle has been tested and discussed. The observed differences in the crack trajectory of different specimens have been found to be related to the magnitude of the higher-order terms of the stress tensor components at the crack tip.
\end{abstract}

KEYwORDS. Crack deflection; DCB specimen; Generalized MTS criterion; Geometry effect; Williams' power expansion.

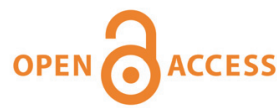

Citation: Malíková, L., Razavi, S.M.J., Berto, F., Crack propagation in a brittle DCB specimen assessed by means of the Williams' power expansion, Frattura ed Integrità Strutturale, 48 (2019) 34-41.

Received: 28.11 .2018

Accepted: 07.01.2019

Published: 01.04.2019

Copyright: (C) 2019 This is an open access article under the terms of the CC-BY 4.0, which permits unrestricted use, distribution, and reproduction in any medium, provided the original author and source are credited.

\section{INTRODUCTION}

s one of the important types of material failure, brittle fracture has been widely taken into consideration by
researchers, trying to propose precise failure prediction criteria for different brittle and quasi-brittle materials such
as rocks, concretes, ceramics and polymers. Dealing with mode I loading condition for a component with
symmetric geometry with respect to the crack line which is under the symmetric loading condition, the crack propagation
from the crack tip is expected to be along the initial plane of the crack. However, previous researches showed that for the 
case of specimens with high geometry constraint, crack can deviate from the symmetry line of the specimen. In this case the fracture load is expected to be different from the specimens with lower constraint effect. It has been shown in previous researches that different fracture toughness values can be obtained for an identical material when using various specimens' geometries [1-9].

This paper shall show differences between the well-known one-parameter fracture mechanics concept and the multiparameter one. Whereas the former one uses the stress intensity factor (SIF) as the single-controlling parameter for assessment of the fracture response of the specimen/structure [10], the latter one is based on the approximation of the stress/displacement crack-tip field by means of the Williams' expansion (WE) [11], i.e. an infinite power series originally derived for a homogeneous elastic isotropic cracked body subjected to an arbitrary remote loading. The multi-parameter concept is very often connected to fracture analyses performed on elastic-plastic or quasi-brittle materials, see e.g. in [1217]. The multi-parameter approach seems to be helpful and more accurate when fracture processes occur in a more distant surrounding around the crack tip. For instance, the influence of the second (non-singular) term of the WE on the fracture behaviour of brittle/quasi-brittle materials has been investigated in several works [18-24].

Ayatollahi et al. [22] proposed two fracture criteria based on strain energy density to take into account the effect of first non-singular term of stress in WE. According to their results higher accuracy of the fracture load prediction can be obtained by use of two parameter fracture criteria. Additionally, unlike the former single parameter fracture criteria, the new formulations were able to successfully predict the curvilinear crack growth path under the influence of geometry constraints.

Razavi et al. [24] evaluated the mode I fracture behavior of five different geometries of pre-cracked specimens made of PMMA and three different rocks using an energy-based criterion namely Average Strain Energy Density (ASED). They reported that for specific categories of materials such as rocks, the effect of geometry constraint is not negligible. Among the studied geometries in their research, application of only the first stress term in Williams' series expansion for fracture prediction of Tapered Double Cantilever Beam (TDCB) specimens made of Harsin marble rock resulted in 47\% difference with the ASED results obtained by considering all stress terms in a control volume around the crack tip for the same specimen.

The basic task, when the WE shall be used for the stress/displacement field approximation, is to determine the coefficients corresponding to the individual terms of the Williams' series. In this paper, the over-deterministic method (ODM) is used [25].

This work is devoted to an investigation of the initial crack propagation angle in several double cantilever beam configurations. The kink angle is estimated by means of the maximum tangential stress criterion [26]. Its common as well as generalized form is applied, and a parametric study is performed in order to describe the effect of the specimen width, the number of terms of the WE taken into account during the analysis and the radial distance from the crack tip where the criterion is applied. The results obtained from the numerical analysis are compared to the experimental ones.

\section{METHODOLOGY AND BASIC TERMS}

\section{Crack-tip fields approximation}

T T illiams [11] showed that the crack-tip displacement/stress field can be described as follows:

$$
\begin{gathered}
u_{i}=\sum_{n=1}^{N} r^{\frac{n}{2}} A_{n} f_{u_{i}}(\theta, n, E, v)+\sum_{m=0}^{M} r^{\frac{m}{2}} B_{m} g_{u_{i}}(\theta, m, E, v) \text { where } i \in\left\{x_{2} y\right\} . \\
\sigma_{i j}=\sum_{n=1}^{N} \frac{n}{2} r^{\frac{n}{2}-1} A_{n} f_{\sigma_{i j}}(\theta, n)+\sum_{m=1}^{M} \frac{m}{2} r^{\frac{m}{2}-1} B_{m} g_{\sigma_{i j}}(\theta, m) \text { where } i, j \in\left\{x_{2} y\right\} .
\end{gathered}
$$

Eqs. 1 and 2 represent the truncated form ( $N$ and $M$ are the numbers of the WE terms corresponding to the loading modes I and II, respectively) of the infinite power series enabling the approximation of the crack-tip fields. Particularly, $u_{i}$ and $\sigma_{i j}$ denote the displacement vector and stress tensor components, respectively. The power series is defined in the polar coordinate system $(r, \theta)$ with its center at the crack tip. The meaning of the other symbols is as follows:

$f_{u}, g_{u} \quad \ldots$ known dimensionless displacements functions corresponding to mode I and II, respectively, that can be found in literature; 
$f_{\sigma}, g_{\sigma} \quad \quad \ldots$ known dimensionless stress functions corresponding to mode I and II, respectively, that can be found in literature;

E, $v \quad \quad$.. Young's modulus and Poisson's ratio;

$A_{n}, B_{m} \quad \ldots$ the only coefficients that need to be calculated numerically for each specific geometric configuration representing the well-known higher-order terms coefficients for mode I and II, respectively.

It should be noted that the first terms of the series, $A_{1}$ and $B_{1}$, correspond to the classical stress intensity factors, $K_{\mathrm{I}}$ and $K_{\mathrm{II}}$, as they are known in the classical one-parameter linear elastic fracture mechanics concept; it holds that $K_{\mathrm{I}}=A_{1} \sqrt{ } 2 \pi$ and $K_{\mathrm{II}}=-B_{1} \sqrt{ } 2 \pi$.

\section{Identification of the coefficients of the Williams' expansion}

It has been mentioned that a very important task is to determine the coefficients of the WE terms correctly. This is mostly performed numerically by means of the finite element (FE) method. Several methods for estimation of the coefficients were derived, tested and applied in the past such as hybrid crack element method, boundary collocation method etc. [2731], but most of them were complicated and demanding special elements or difficult FE formulations.

In this work, an over-deterministic method (ODM) [25] is applied because of its simplicity. This procedure is based on the formulation of linear least-squares and it requires the basic nodal solution of the fracture mechanics task. Therefore, an arbitrary regular FE code can be utilized for its application. The use of the method consists in definition of the displacement field around the crack tip, see Eq. 1.

When the numerical analysis on the cracked specimen/structure is carried out, a set of nodes around the crack tip is selected and their displacements together with their polar coordinates are taken as inputs for Eq. 1. The only variables $A_{n}$ and $B_{m}$ can be then calculated from the system of equations. The principle of the ODM lies in the relation between the number of the equations and number of the coefficients that shall be determined: a minimum of $(N+M) / 2+1$ nodes need to be considered in order to determine $N+M$ coefficients. More investigations on the accuracy, convergence, mesh sensitivity, influence of the rounding of numbers etc. can be found in [32-35].

\section{Maximum Tangential Stress (MTS) criterion}

MTS criterion predicts that a crack propagates in the direction where the tangential stress, $\sigma_{\theta \theta}$, reaches its maximum [26]. In the classical one-parameter fracture mechanics concept an explicit relation for the kink angle has been derived:

$$
\gamma=2 \arctan \frac{-2 K_{\mathrm{II}}}{K_{\mathrm{I}}+\sqrt{K_{\mathrm{I}}^{2}+8 K_{\mathrm{II}}^{2}}}
$$

Nevertheless, because the multi-parameter concept is used in this work, the tangential stress values must be approximated via Williams' power expansion considering various numbers of the initial WE terms and then the initial crack propagation angle has been estimated. Note that a new dependence arises during this procedure: the initial kink angle depends on the distance where the criterion is applied and therefore various distances from the crack tip are considered in the analysis, see the following sections.

\section{SPECIMEN GEOMETRY/NUMERICAL MODEL}

7 he Double Cantilever Beam (DCB) type of the cracked specimen was chosen for the study presented taking into account various crack width $W(30,90$ and $150 \mathrm{~mm})$, see Fig. 1. The major advantage for choosing this type of specimens is that they are characterized by simple shapes and loading conditions, while they can provide a wide range of higher-order terms of stress in WE. The test specimens were cut from $10 \mathrm{~mm}$ thick PMMA plate and tested under static loading at room temperature with a displacement rate of $0.1 \mathrm{~mm} / \mathrm{min}$. As is reported in ref. [36], the specimens were all fractured suddenly from the crack tip and with linear load-displacement curves confirming the brittle fracture behavior of the tested PMMA samples. The experimental setup is described in detail in ref. [36]. For creating the cracks, first a very thin strip saw blade of thickness $0.2 \mathrm{~mm}$ was used to create a notch with an initial depth slightly less than $a / W=0.5$. Then, a sharp crack was created by pressing a razor blade carefully to make the final crack length of each specimen equal to $a / W=0.5$. The external load was applied through two pin holes devised on each specimen. 


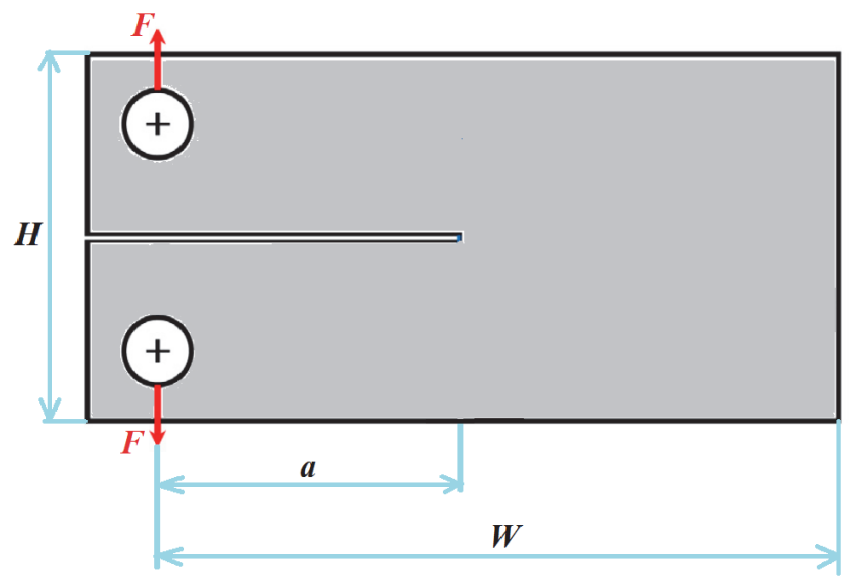

Figure 1: Schema of the Double Cantilever Beam (DCB) specimen with its sizes: width $W$, height $H$, crack length $a$ and loading forces F.

The numerical analysis (as well as experiments) was performed on the specimens with following dimensions and parameters: specimen height $H=30 \mathrm{~mm}$, specimen width $W=30,90$ and $150 \mathrm{~mm}$, specimen thickness $B=10 \mathrm{~mm}$, crack length $a=W / 2$. The value of the loading force was chosen with regard to the fracture force leading to crack propagation observed during the experimental research presented in [36], $F=319,141$ and $87 \mathrm{~N}$ (corresponding to the specimen width 30,90 and $150 \mathrm{~mm}$ ).

In order to get the nodal displacements that are necessary for ODM application, a numerical model of the cracked specimen was created in ANSYS commercial software [37] with the following features: 2D, linear elastic, meshed with quadratic PLANE183 elements, refined mesh around the crack tip (with shifted mid-side nodes emphasizing the stress singularity), plane strain conditions, Young's modulus $E=2900 \mathrm{MPa}$ and Poisson's ration $v=0.35$. Subsequently, the ODM procedure was programmed in Wolfram Mathematica software [38]. For estimation of the coefficients of the WE, the nodes with their coordinates and displacements at the distance of $1 \mathrm{~mm}$ from the crack tip were utilized. A typical mesh pattern used for finite element analysis is illustrated in Fig. 2. As can be observed from Fig. 2, higher density of elements has been used for the area near the crack tip to get accurate results in the region with singular stress values.
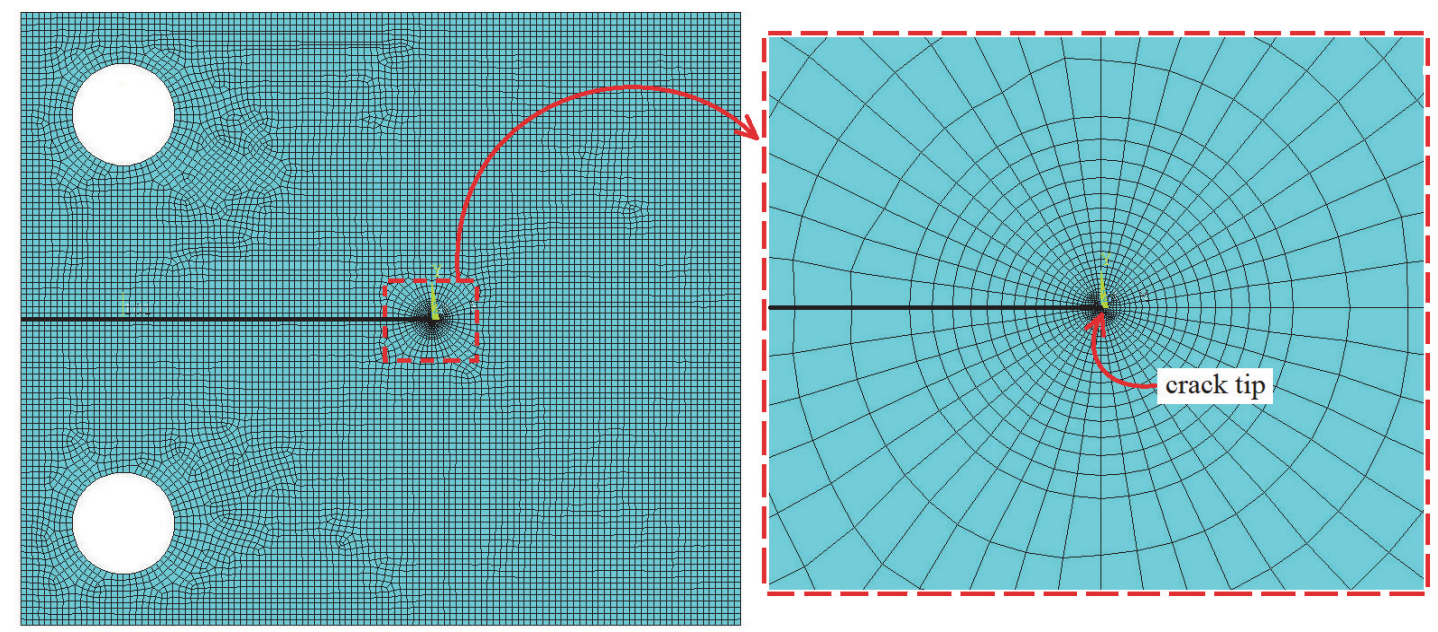

Figure 2: Typical mesh pattern used for finite element analysis of the cracked specimen.

The maximum tangential stress criterion was applied in the following manner. The tangential stress around the crack tip at various radial distances $r_{c}$ in the range from 0.1 to $1 \mathrm{~mm}$ was reconstructed by means of the Williams' power series. The angle $\theta$, where the $\sigma_{\theta \theta}$ reaches its maximum value was selected as the direction of the further crack propagation. During application of the multi-parameter/generalized fracture criterion, various numbers of the WE terms were assumed (up to 10 initial terms). 


\section{RESULTS OF THE PARAMETRIC STUDY AND THEIR DISCUSSION}

$\mathrm{I}$ $\mathrm{n}$ the following results, only the dependences for the DCB specimens with the width 90 and $150 \mathrm{~mm}$ are presented. The reason is that when the crack propagation in the DCB specimen with $W=30 \mathrm{~mm}$ was investigated, no deviation from the original crack plane was observed, i.e. the crack propagates in the original direction regardless the distance of the crack tip where the criterion is applied as well as the number of the WE terms considered.

In Figs. 3 and 4 the dependences of the initial crack direction on the number of the WE terms considered and critical distance from the crack tip where the MTS criterion is applied are presented. In the figures only the data obtained from numerical analysis are plotted. The values of the initial crack propagation angle observed during experiments are 0,9 and 56 degrees for $W=30,90$ and $150 \mathrm{~mm}$, respectively [36], for comparison see the black lines in Fig. 4.

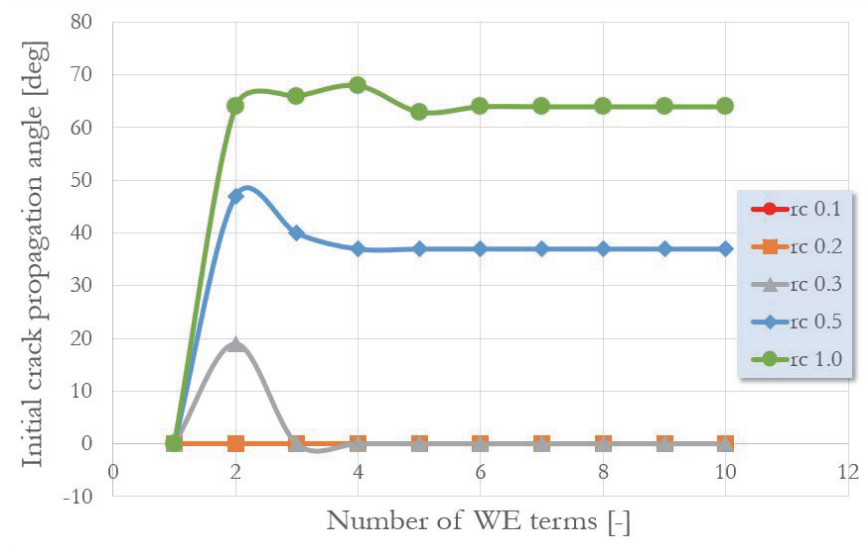

a)

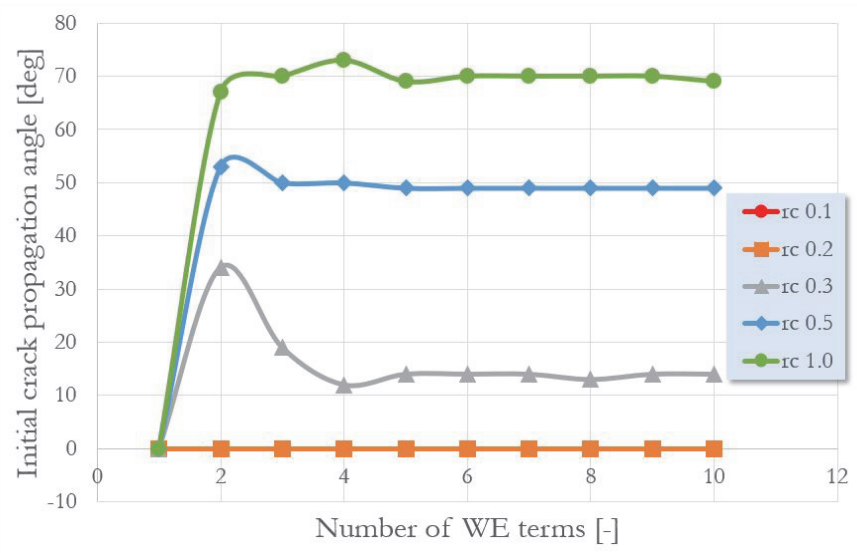

b)

Figure 3: Dependence of the initial crack propagation angle estimated by means of the multi-parameter maximum tangential stress criterion on the number of the WE terms considered when various critical distances from the crack tip are assumed: a) DCB with $W=90 \mathrm{~mm}$; b) DCB with $W=150 \mathrm{~mm}$.

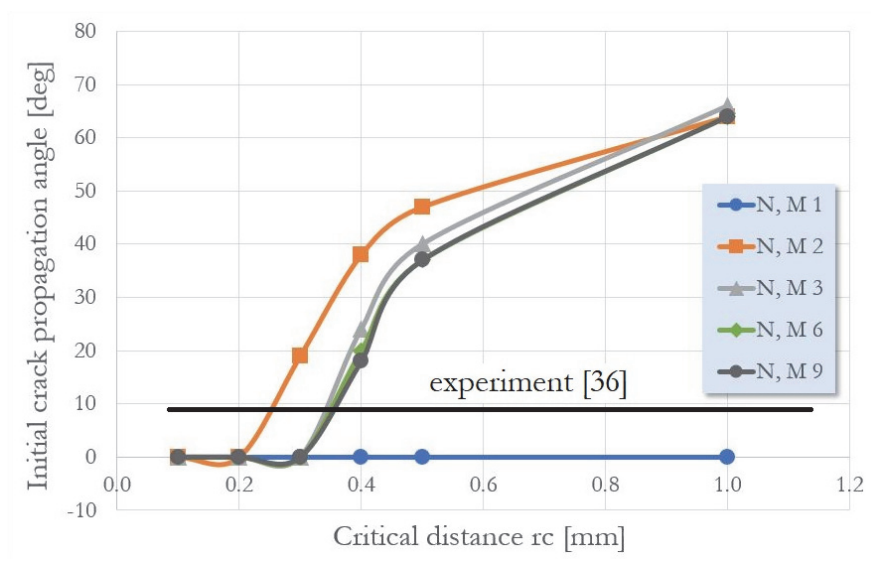

a)

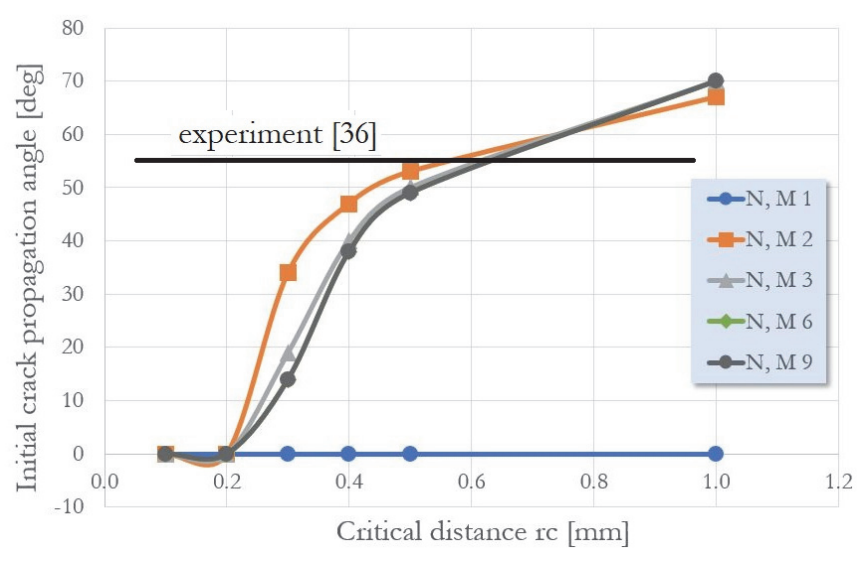

b)

Figure 4: Dependence of the initial crack propagation angle estimated by means of the multi-parameter maximum tangential stress criterion on the radial distance from the crack tip when various numbers of the WE terms are considered: a) DCB with $W=90$ mm; b) $\mathrm{DCB}$ with $W=150 \mathrm{~mm}$.

The generalized strain energy density (GSED) criterion is moreover used for estimation of the initial kink angle in [36] and the results correspond well with the experiment (considering the critical distance of $0.1 \mathrm{~mm}$ ). Unfortunately, information about the dependence of the results on the critical distance value is missing. But the GSED seems to be a useful tool for calculation of the crack propagation angle. Application of the generalized MTS criterion introduced in this paper depends strongly on the choice of the critical distance and therefore attention should be devoted to this phenomenon. 
It should be also mentioned that the fracture load of a brittle material is commonly obtained using single parameter fracture criteria which are formulated based on the critical values of stress intensity factor corresponding to the fracture load of the material. Although the main focus of the current research is on crack kinking angle, however, it is expected to get more accurate results of fracture load by considering higher-order terms of WE in calculations.

According to the results presented in this paper, considering the higher-order terms of WE in calculation of initial crack propagation angle leads to more accurate crack trajectory predictions. Hence, the single parameter fracture criteria can provide reliable fracture predictions only for limited range of geometries.

Based on the results introduced, several statements can be formulated:

- Probably the most important conclusion is that the classical (one-parameter) MTS criterion is not able to describe the crack deflection when DCB specimens with larger width (i.e. higher geometric constraints) are investigated. The classical MTS criterion predicts that the crack will propagate in its original direction without any kinking for all the DCB cofigurations considered. Nevertheless, the experiments show that for specimens with the width 90 and $150 \mathrm{~mm}$ the crack deviates from its original plane.

- The results also show that when the MTS criterion is applied at distances very close to the crack tip, the singularity of the first WE terms prevails and the criterion does not describe the crack kinking.

- The initial increase of the estimated initial kink angle in Fig. 3 is probably connected to a certain region around the crack tip, where the second term of the WE (non-singular T-stress) becomes important. This phenomenon can be seen also in Fig. 4, where the curve representing the results corresponding to the approximation by means of initial two terms lies higher than other curves in a certain region of distances from the crack tip. The theoretical effect of the large $T$-stress on the crack propagation under mode $I$ is described in detail in [39].

- A good agreement between the results of the generalized MTS criterion and the experimantal campaign can be found for the critical distance of $0.5 \mathrm{~mm}$ in the case of DCB specimens with $W=150 \mathrm{~mm}$, and for critical distance between 0.3 and $0.5 \mathrm{~mm}$ in the case of DCB specimens with $W=90 \mathrm{~mm}$.

- The initial kink angle calculated by means of the multi-parameter MTS criterion considering 3 WE and more than $3 \mathrm{WE}$ terms does not change significantly when more than $3 \mathrm{WE}$ terms are cosidered, see the steadying of the curves in Fig. 3 and overlaping of the curves in Fig. 4.

- It has been reported by Ayatollahi et al. [16, 30] that for materials with larger fracture process zone radius, e.g. rock materials, the higher-order terms of WE becomes no longer negligible in overal fracture behaviour of the component. Hence, the higher-order terms of stress can play an important role in fracture strength and crack trajectory of materials possessing larger fracture process zone. In that case, the importance of using a fracture criterion, which counts for higher-order terms, would be even more important.

- Although the current methodology is presented for a specific brittle polymer, (i.e. PMMA), however, the same method can be employed to predict the fracture trajectory of other cracked and notched components made of brittle and quasi-brittle materials. Note that the significance of the $T$-stress has been investigated intensively in [40]. where a mixed-mode loading configuration was analysed.

- The crack kinking angles for different test specimens are predicted in the current research by considering the higher-order terms of WE series. The same methodology can be used to get the full crack path by use of the incremental method in finite element software and predicting the crack growth angle for each crack increment.

\section{CONCLUSIONS}

V arious DCB specimen configurations have been investigated by means of numerical methods in order to estimate the angle of the initial crack propagation. Although the crack in the DCB specimen is loaded in the mode I, it is experimentally observed, that for DCB specimens with larger width (90 and $150 \mathrm{~mm})$, the crack deflects from its original direction. In this parametrical study this phenomenon is described by means of the generalized form of the wellknown MTS criterion because the classical (one-parameter) form of the criterion is not able to describe the crack deflection. It can be recommended for DCB specimens with higher constraint effects to use the multi-parameter form of the MTS criterion with at least three initial WE terms to get better results of the kink angle. It is also shown that the choice of the appropriate critical distance where the fracture criterion is applied is crucial. Based on this study, the critical distance close to $0.5 \mathrm{~mm}$ seems to be optimal for the considered material. 


\section{ACKNOWLEDGMENT}

he work has been supported by the Czech Science Foundation (project No. 18-12289Y) and the support is gratefully acknowledged.

\section{REFERENCES}

[1] Larsson, S.G., Carlsson, A.J. (1973). Influence of non-singular stress and specimen geometry on small-scale yielding at each tip in elastic-plastic materials, J. Phys. Solids, 21, pp. 263-277.

[2] Moattari, M., Sattari-Far, I. (2017). Modification of fracture toughness Master Curve considering the crack-tip Qconstraint, Theor. Appl. Fract. Mech., 90, pp. 43-52.

[3] Kumar, B., Chitsiriphanit, S., Sun, C.T. (2011). Significance of K-dominance zone size and nonsingular stress field in brittle fracture, Eng. Fract. Mech., 78, pp. 2042-2051.

[4] Rice, J.R. (1974). Limitations to the small scale yielding for crack-tip plasticity, J. Mech. Phys. Solids, 22, pp. 17-26.

[5] Betegon, C., Hancock, J.W. (1991). Two-parameter characterization of elastic-plastic crack-tip fields, J. Appl. Mech., 58, pp. 104-110.

[6] Du, Z.Z., Hancock, J.W. (1991). The effect of non-singular stresses on crack tip constraint, J. Mech. Phys. Solids, 39, pp. $555-567$.

[7] Sun, C.T., Qian, H. (2009). Brittle fracture beyond the stress intensity factor, J. Mech. Mater. Struct., 4, pp. $743-753$.

[8] Liu, S., Chao, Y.J. (2003). Variation of fracture toughness with constraint, Int. J. Fract., 124, pp. $113-117$.

[9] Chao, Y.J., Liu, S., Broviak, B.J. (2001) Brittle fracture: variation of fracture toughness with constraint and crack curving under mode I conditions, Exp. Mech., 41, pp. 232-241.

[10] Anderson, T.L. (2004). Fracture mechanics: Fundamentals and Applications, CRC Press, Boca Raton.

[11] Williams, M.L. (1957). On the stress distribution at the base of a stationary crack, J. Appl. Mech., 24, pp. 109-114.

[12] Ayatollahi, M.R., Akbardoost, J. (2012). Size effects on fracture toughness of quasi-brittle materials - A new approach, Engng. Fract. Mech., 92, pp. 89-100.

[13] Berto, F., Lazzarin, P. (2010). On higher order terms in the crack tip stress field, Int. J. Fract., 161, pp. $221-226$.

[14] Stepanova, L., Roslyakov, P. (2016). Complete Williams Asymptotic Expansion Near the Crack tips of Collinear Cracks of Equal Lengths in an Infinite, Proc. Struct. Int., 2, pp. 1789-1796.

[15] Stepanova, L., Roslyakov, P. (2016). Multi-parameter description of the crack-tip stress field: Analytic determination of coefficients of crack-tips stress expansions in the vicinity of the crack tips of two finite in an infinite plane medium, Int. J. Solids Struct., 100-101, pp 11-28.

[16] Veselý, V., Frantík, P., Sobek, J., Malíková, L., Seitl, S. (2015). Multi-parameter crack tip stress state description for evaluation of nonlinear zone width in silicate composite specimens in component splitting/bending test geometry, Fatigue Fract. Engng. Mat. Struct., 38(2), pp. 200-214.

[17] Veselý, V., Sobek, J., Šestáková, L., Frantík, P., Seitl S. (2013). Multi-parameter crack tip stress state description for estimation of fracture process zone extent in silicate composite WST specimens, Fratt. Int. Strutt., 7(25), pp. 69-78.

[18] Shahani, A.R., Tabatabaei, S.A. (2009). Effect of T-stress on the fracture of a four-point bend specimen, Mat. Design, 30, pp. 2630-2635.

[19] Ševčík, M., Hutař, P., Náhlík, L., Seitl, S. (2013). The effect of constraint level on a crack path, Engng. Fract. Mech., 29, pp. 83-92.

[20] (Šestáková) Malíková, L. (2013). Crack path investigation using the generalized maximum tangential stress criterion: antisymmetrical four-point bending specimen, Key Engng. Mat., 436, pp. 108-113.

[21] Roux-Langlois, C., Gravouil, A., Baietto, M.C., Réthoré, J., Mathieu, F., Hild, F., Roux, S. (2015). DIC identification and X-FEM simulation of fatigue crack growth based on the Williams' series, Int. J. Solids Struct., 53, pp. 38-47.

[22] Ayatollahi, M.R., Razavi, S.M.J., Rashidi Moghaddam, M., Berto, F. (2015). Mode I Fracture Analysis of Polymethylmetacrylate Using Modified Energy-Based Models, Phys. Mesomech., 18(4), pp. 326-336.

[23] Rashidi Moghaddam, M., Ayatollahi, M.R., Razavi, S.M.J., Berto, F. (2017). Mode II brittle fracture assessment using an energy based criterion, Phys. Mesomech., 20(2), pp. 142-148.

[24] Razavi, S.M.J., Ayatollahi, M.R., Berto, F. (2018). A synthesis of geometry effect on brittle fracture, Eng. Fract. Mech., 187, pp. 94-102. 
[25] Ayatollahi, M.R., Nejati, M. (2011). An over-deterministic method for calculation of coefficients of crack tip asymptotic field from finite element analysis, Fatigue Fract. Engng. Mat. Struct., 34(3), pp. 159-176.

[26] Erdogan, F., Sih, G.C. (1963). On the crack extension in plates under plane loading and transversal shear, J. Basic Engng., 85, pp. 519-527.

[27] Xiao, Q.Z., Karihaloo, B.L. (2007) An overview of a hybrid crack element and determination of its complete displacement field, Engng. Fract. Mech., 74, pp. 1107-1117.

[28] Karihaloo, B.L., Xiao, Q.Z. (2011). Higher order terms of the crack tip asymptotic field for a notched three-point bend beam, Int. J. Fract., 112(2), pp. 111-128.

[29] Knésl, Z. (1994/1995). Evaluation of the elastic T-stress using a hybrid finite element approach, Int. J. Fract., 70(1), pp. R9-R14.

[30] Tong, P., Pian, T.H.H., Lasry, S.J. (1973). A hybrid element approach to crack problems in plane elasticity, Int. J. Num. Methods Engng., 7, pp. 297-308.

[31] Xiao, Q.Z., Karihaloo, B.L., Liu, X.Y. (2004). Direct determination of SIF and higher order terms of mixed mode cracks by a hybrid crack element, Int. J. Fract., 125, pp. 207-225.

[32] Malíková, L. (2.015) Multi-parameter fracture criteria for the estimation of crack propagation direction applied to a mixed-mode geometry, Engng. Fract. Mech., 143, pp. 32-46.

[33] Šestáková (Malíková), L. (2013). How to enhance efficiency and accuracy of the over-deterministic method used for determination of the coefficients of the higher-order terms in Williams expansion, Appl. Mech. Mat., 245, pp. 120125.

[34] Šestáková, L., Veselý, V. (2013). Convergence study on application of the over-deterministic method for determination of near-tip fields in a cracked plate loaded in mixed-mode, Appl. Mech. Mat., 249-250, pp. 76-81.

[35] Růžička, V., Malíková, L., Seitl, S. (2017). Over-deterministic method: The influence of rounding numbers on the accuracy of the values of Williams' expansion terms, Fratt. Integrità Strutt., 42, pp. 128-135.

[36] Ayatollahi, M.R., Moghaddam, M.R., Razavi, S.M.J., Berto, F. (2016). Geometry effects on fracture trajectory of PMMA samples under pure mode-I loading, Engng. Fract. Mech., 163, pp. 449-461.

[37] ANSYS Program Documentation (2005). User's manual version 10.0. Swanson Analysis System, Inc., Houston.

[38] Information on https://www.wolfram.com/mathematica/.

[39] Ayatollahi, M.R., Pavier, M.J., Smith, D.J. (2002). Mode I cracks subjected to large T-stresses, Int. J. Fract., 117, pp. 159-174.

[40] Smith, D.J., Ayatollahi, M.R., Pavier, M.J., (2001). The role of T-stress in brittle fracture for linear elastic materials under mixed-mode loading, Fatigue Fract. Engng. Mat. Struct., 24, pp. 137-150. 